\title{
Enhanced tumor necrosis factor- $\alpha$-specific and decreased interleukin-10-specific immune responses to LPS during the third trimester of pregnancy in mice
}

\author{
E S Vizi ${ }^{1}$, J Szelényi ${ }^{1}$, Zs Selmeczy ${ }^{1}$, Z Papp $^{2}$, Z H Németh ${ }^{1,3}$ \\ and G Haskó ${ }^{1,3}$ \\ ${ }^{1}$ Department of Pharmacology, Institute of Experimental Medicine, Hungarian Academy of Sciences, H-1450 Budapest, POB 67, Hungary \\ ${ }^{2}$ First Department of Obstetrics and Gynecology, Semmelweis University, Faculty of Medicine, Budapest, H-1088 Budapest, Baross u. 27 , Hungary \\ ${ }^{3}$ Department of Surgery, UMD-New Jersey Medical School, Newark, New Jersey 07103, USA \\ (Requests for offprints should be addressed to E S Vizi, Institute of Experimental Medicine, Hungarian Academy of Sciences, PO Box 67, H-1450 Budapest, \\ Hungary; Email: esvizi@koki.hu)
}

\begin{abstract}
It is increasingly apparent that there is a bidirectional interaction between the maternal immune system and the reproductive system during pregnancy. Pregnancy is associated with a suppression of maternal specific immune responses, which process underlies the protection of fetal tissues expressing paternally inherited alloantigens. However, recent evidence indicates that the suppression of specific, lymphocyte-mediated immune responses during pregnancy is accompanied by activation of the nonspecific arm of the maternal immune response. In the present study, we have investigated the effect of pregnancy on the non-specific immune response induced by bacterial lipopolysaccharide (LPS, endotoxin) in mice. Pregnancy enhanced the LPS-induced production of proinflammatory cytokines, including tumor necrosis factor- $\alpha$, interleukin (IL)-6, and interferon- $\gamma$. On the other hand,
\end{abstract}

LPS-induced levels of the anti-inflammatory cytokine IL-10 were suppressed in pregnant mice. These alterations in cytokine production correlated with an increased susceptibility for endotoxemic mortality in the pregnant mice. Although adrenergic receptors are important regulators of cytokine production in non-pregnant mice, the $\alpha_{2^{-}}$and the $\beta$-adrenoceptor-mediated modulation of cytokine production ceases to operate during pregnancy associated with severe endotoxemia. These data may explain how excessive activation of the non-specific immune responses during pregnancy can contribute to the increased severity of some maternal diseases, including septic shock, and can be an important pathophysiological factor in disseminated intravascular coagulation or preeclampsia.

Journal of Endocrinology (2001) 171, 355-361

\section{Introduction}

In his classic 1953 paper, Medawar proposed the concept of the 'fetal allograft' to explain the immune relationship between mother and fetus. In this model, immunological interaction between mother and fetus is suppressed, through either lack of fetal-antigen presentation to maternal lymphocytes or maternal lymphocyte suppression.

Subsequently, this view of a generalized lymphocyte anergy during pregnancy became more refined, as it was suggested that maternal immune responses would be biased from a $\mathrm{T}$ helper (Th)1-type cellular response to a Th2-type, less damaging humoral response (Wegmann et al. 1993). These observations are consistent with clinical evidence that pregnant women with rheumatoid arthritis (a Th1-type autoimmune disease) experience a temporary remission of their symptoms, whereas the severity of systemic lupus erythematosus (a mainly Th2-driven disease) tends to be exacerbated during pregnancy (Ostensen 1999).

Although such a decrease in lymphocyte responsiveness explains some of the clinical findings observed in pregnancy, there are a number of observations suggesting that the model of a shifted Th1/Th2 response does not fully explain the substantial changes in maternal immune system function. For example, if a decrease in Th1-type immune responses is the dominant feature of the pregnant immune system, then it would be expected that pregnant women would be more susceptible to infection with a variety of intra- and extracellular pathogens. However, this is not the case, because despite the decreased production of Th1 cytokines, pregnant women are relatively resistant to overwhelming infection (Sacks et al. 1999). Furthermore, in the experimental Shwartzmann reaction, pregnant animals, far from being immunosuppressed, are 
uniquely primed to respond, often fatally, to just a single injection of endotoxin (Mori 1981).

To explain these phenomena, Sacks et al. (1999) proposed a new paradigm for the maternal immune response. According to this paradigm, the specific, lymphocytemediated arm of the immune response is accompanied, and perhaps compensated, by the activation of the nonspecific immune system, in which the monocyte/ macrophage and granulocyte rather than the lymphocyte assumes a central role in immunological adaptation. In support of this hypothesis, there is a plethora of data demonstrating that the maternal non-specific immune system is activated during pregnancy. For instance, in normal pregnancy, circulating monocytes and granulocytes in whole blood have activated phenotypes, in some ways comparable with changes observed in systemic inflammatory states. These inflammatory changes consist of an increase in the numbers and phagocytotic capacity of monocytes and granulocytes (Koumandakis et al. 1986), enhanced expression of CD11b, CD14 and CD64 (Sacks et al. 1998, Faas et al. 2000) and an increase in intracellular reactive oxygen species (Sacks et al. 1998, Faas et al. 2000). Importantly, the increased expression of CD11b, CD14 and intracellular reactive oxygen species is even more pronounced in preeclampsia than in normal pregnancy (Redman et al. 1999).

Based on the above evidence documenting that various inflammatory functions of the innate immune system are upregulated during pregnancy, we hypothesized that pregnancy would increase systemic levels of inflammatory cytokines derived from cells of the innate immune system. The data presented in this paper demonstrate that in an endotoxemic model of the systemic inflammatory response of the innate immune system, the production of monocyte/macrophage/neutrophil-derived proinflammatory cytokines, including tumor necrosis factor (TNF)- $\alpha$ and interleukin (IL)-6, as well as interferon (IFN)- $\gamma$, is greatly increased in pregnant mice. On the other hand, in contrast to the generally held view that pregnancy is characterized by increased IL-10 production (Elenkov et al. 1997), we show that the levels of IL-10 are substantially blunted in endotoxemic pregnant mice. Finally, we provide evidence that not only the production of inflammatory cytokines is altered in pregnant mice as compared with non-pregnant mice, but that some of the endogenous regulatory mechanisms provided by the sympathetic nervous system that control cytokine production in non-pregnant mice are lost in pregnant mice.

\section{Materials and Methods}

\section{Animals}

Swiss mice (20-30 g) were purchased from Charles River Laboratories (Budapest, Hungary) and kept in the Animal Care Unit for 7 days before use. Animals received food and water freely, and lighting was maintained on a $12 \mathrm{~h}$ cycle. The female mice were caged for $24 \mathrm{~h}$ with the male mice and then checked for the presence of a vaginal plug. The pregnant group was composed of those female mice that were positive for the presence of a vaginal plug, while the others formed the control, non-pregnant group. In this respect, the assignment of the animals was not random. The experiments were carried out on 17-18 day pregnant mice. These animals are referred to in the text as pregnant mice in the third trimester; 7-8 day pregnant mice were taken as pregnant animals in the first trimester. The animal experiments described in this article were performed with adherence to National Institutes of Health guidelines on the use of experimental animals. Approval of the Animal Use Committee of the Institute of Experimental Medicine, Hungarian Academy of Sciences was obtained prior to initiating the experiments.

\section{Experimental design for plasma cytokine measurements}

Animals were injected i.p. with drug vehicle (sterile physiological saline) or drugs in a volume of $0.1 \mathrm{ml} / 10 \mathrm{~g}$ body weight. Thirty minutes later, they were challenged with 10 or $50 \mathrm{mg} / \mathrm{kg}$ of bacterial lipopolysaccharide (LPS) administered i.p. Animals were killed $90 \mathrm{~min}$ or $4 \mathrm{~h}$ after LPS treatment, if not otherwise indicated. The $90 \mathrm{~min}$ and $4 \mathrm{~h}$ time points represent the peak response of the production of TNF- $\alpha$ and IL-10 respectively in response to a single dose of LPS (Elenkov et al. 1995, Haskó et al. 1995, 1996, 1998). Propranolol (10 mg/kg), a $\beta$-adrenoceptorblocking drug, or $\mathrm{CH}-38083(10 \mathrm{mg} / \mathrm{kg})$, a selective $\alpha_{2}$-adrenoceptor-blocking drug (Vizi et al. 1986), was injected $30 \mathrm{~min}$ before LPS. Blood was collected in ice-cold Eppendorf tubes containing heparin and centrifuged for $10 \mathrm{~min}$ at $4{ }^{\circ} \mathrm{C}$. The plasma was stored at $-70{ }^{\circ} \mathrm{C}$ until assayed.

\section{Cytokine assays}

Plasma levels of cytokines (TNF- $\alpha$, IL-6, IFN- $\gamma$, IL-10 and IL-1 $\alpha$ ) were determined using a solid-phase enzyme immunoassay, employing the multiple antibody sandwich principle that specifically detects murine cytokines (Genzyme Corp., Boston, MA, USA). The standard error of the mean (s.E.M.) of duplicate samples for cytokine readings was $\pm 5 \%$. Absorbance was recalculated as concentration $(\mathrm{ng} / \mathrm{ml})$ using a standard curve by Microplate Manager/PC Data Analysis Software (BioRad, Richmond, CA, USA). Plates were read at $450 \mathrm{~nm}$ by a Spectramax 250 microplate reader (Molecular Devices, Sunnyvale, CA, USA). Detection limits were $15 \mathrm{pg} / \mathrm{ml} \mathrm{TNF}-\alpha, 10 \mathrm{pg} / \mathrm{ml} \mathrm{IL-6,} 5 \mathrm{pg} / \mathrm{ml} \mathrm{IFN}-\gamma$ and $15 \mathrm{pg} / \mathrm{ml}$ IL-10. Assays were performed according to the manufacturer's instructions and as described in our previous studies (Haskó et al. 1996, 2000). 


\section{Endotoxin-induced lethality studies}

Pregnant or non-pregnant mice were subjected to an i.p. LPS challenge $(50 \mathrm{mg} / \mathrm{kg})$. Survival was recorded 24, 48, $72,96 \mathrm{~h}$ and 2 weeks after the LPS injection.

\section{Drugs}

LPS from Escherichia coli 055:B5, purchased from Sigma Chemical Co. (St Louis, MO, USA), was dissolved in distilled water; the mixture was sonicated for at least $3 \mathrm{~min}$ in a sonication bath, and aliquots were stored at $-40{ }^{\circ} \mathrm{C}$ until use. After they were thawed, appropriate dilutions were made in saline in polypropylene tubes. CH-38083 (7,8-(methylenedioxy)-14a-hydroxyalloberbane $\mathrm{HCl}$ ) was obtained from Chinoin (Budapest, Hungary). Propranolol, isoproterenol and EDTA dipotassium salt were purchased from Research Biochemical International (Natick, MA, USA). Drugs were dissolved in saline on the day of experiment and used immediately.

\section{Statistical evaluation}

Values in the figures and text are expressed as mean \pm S.E.M. of $n$ observations. Statistical analysis of the data was performed by the Student's unpaired $t$-test or the Mann-Whitney test, as appropriate. $P<0.05$ was considered statistically significant.

\section{Results}

Effect of LPS on plasma level of cytokines in control and pregnant mice

i.p. injection of $50 \mathrm{mg} / \mathrm{kg}$ LPS resulted in appearance of increased plasma levels of TNF- $\alpha$ and IL-10 in non-pregnant mice at $90 \mathrm{~min}$ after the LPS challenge (Fig. 1). Although levels of both cytokines were not detected in both pregnant and non-pregnant mice challenged with the vehicle for LPS (physiological saline; data not shown), pregnant mice produced significantly more TNF- $\alpha$ and significantly less IL-10 than non-pregnant mice in response to LPS as determined $90 \mathrm{~min}$ after LPS exposure (Fig. 1A and B). At $4 \mathrm{~h}$ after LPS, the suppressive effect of pregnancy on IL-10 production was even more pronounced (Fig. 1C), whereas TNF- $\alpha$ levels were not detected in either group (not shown). In addition, following LPS challenge, the plasma levels of IL-6 and IFN- $\gamma$ were much higher in pregnant mice than in control animals (Table 1). In contrast, no difference was seen between non-pregnant and pregnant animals when IL-1 $\alpha$ plasma levels were assayed (Table 1). Finally, the TNF- $\alpha$ response to LPS was significantly higher in pregnant mice than in their controls
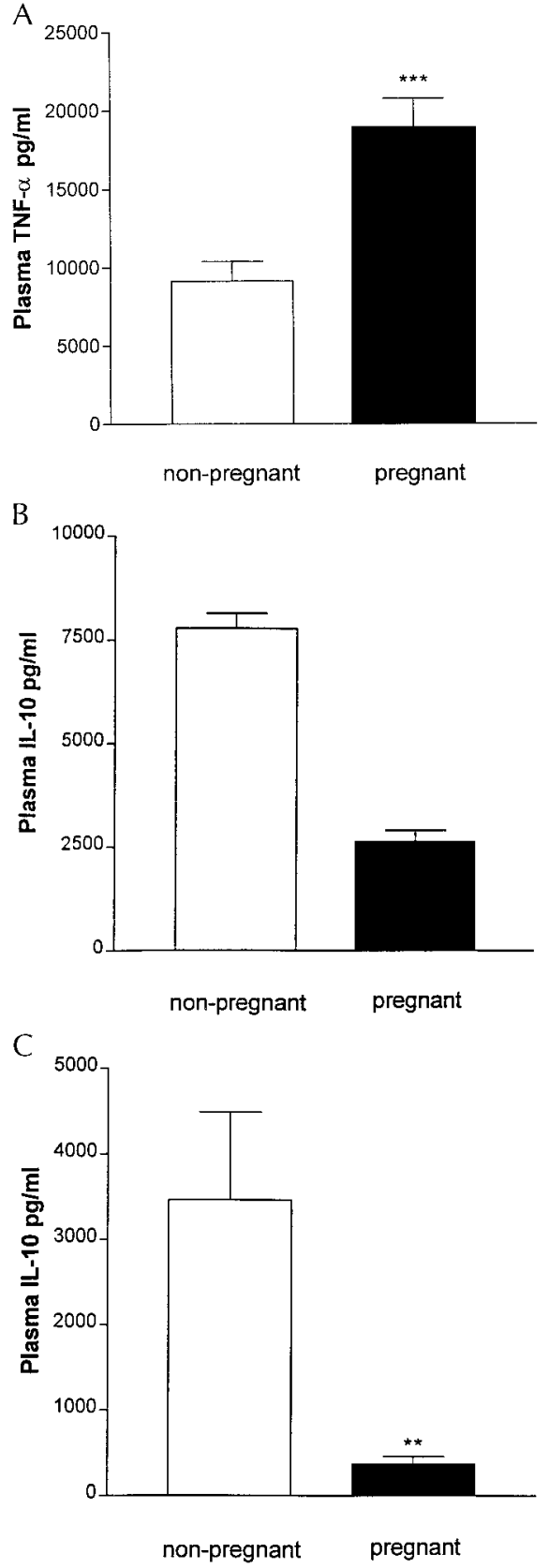

Figure 1 Plasma levels of TNF- $\alpha$ (A) and IL-10 (B and C) in non-pregnant and pregnant mice in response to LPS administered at a dose of $50 \mathrm{mg} / \mathrm{kg}$ (i.p.). The plasma was collected $90 \mathrm{~min}$ (A and $\mathrm{B}$ ) or $4 \mathrm{~h}(\mathrm{C})$ after LPS injection. Note that TNF- $\alpha$ response to LPS was significantly higher and that of IL-10 was significantly lower. ${ }^{* *} P<0 \cdot 01,{ }^{* *} P<0001 . n=8-10$ per group.

even in the first trimester (Fig. 2). Taken together, pregnancy augments the production of the proinflammatory cytokines TNF- $\alpha$, IL-6 and IFN- $\gamma$, but suppresses the production of the anti-inflammatory cytokine IL-10. 
Table 1 Changes in the LPS-evoked $(50 \mathrm{mg} / \mathrm{kg}$ ) response of inflammatory mediator levels in pregnancy (third trimester). Plasma levels ( $\mathrm{pg} / \mathrm{ml} \pm$ S.D.) were assayed $240 \mathrm{~min}$ (IL-1 $\alpha$ and IFN- $\gamma$ ) and 90 min (IL-6) after LPS injection. Number of mice in brackets

\begin{tabular}{|c|c|c|c|}
\hline & IL-1- $\alpha$ & IL-6 & IFN- $\gamma$ \\
\hline Non-pregnant & $70 \cdot 3 \pm 35 \cdot 9(8)$ & $42300 \pm 12700(10)$ & $104 \cdot 9 \pm 83 \cdot 0(10)$ \\
\hline Pregnant & $89 \cdot 4 \pm 43 \cdot 2(8)$ & $113270 \pm 4073(10)^{*}$ & $182 \cdot 8 \pm 89 \cdot 6(10)^{*}$ \\
\hline
\end{tabular}

${ }^{*} P<0 \cdot 01$.

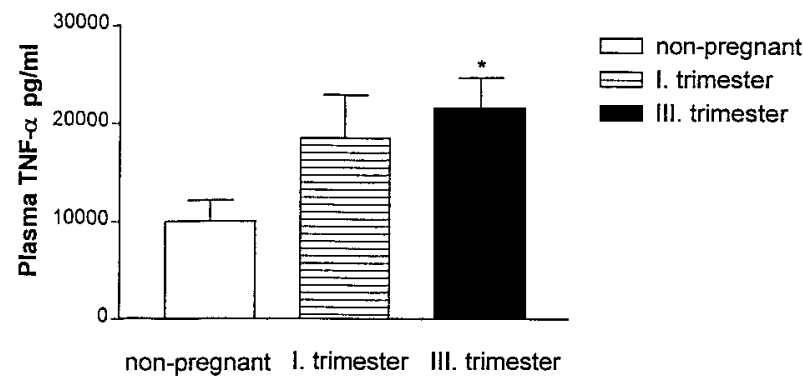

Figure 2 Changes in plasma levels of TNF- $\alpha$ following i.p. administration of LPS at a dose of $10 \mathrm{mg} / \mathrm{kg}$ in the third trimester. First trimester: 7-8 days of pregnancy. Third trimester: 17-18 days of pregnancy. $n=8-10$ per group. ${ }^{*} P<0 \cdot 05$.

\section{Pregnancy increases mortality in LPS-treated mice}

Because pregnancy skewed the cytokine response towards a proinflammatory profile, we hypothesized that pregnancy would increase LPS-induced lethality. Figure 3

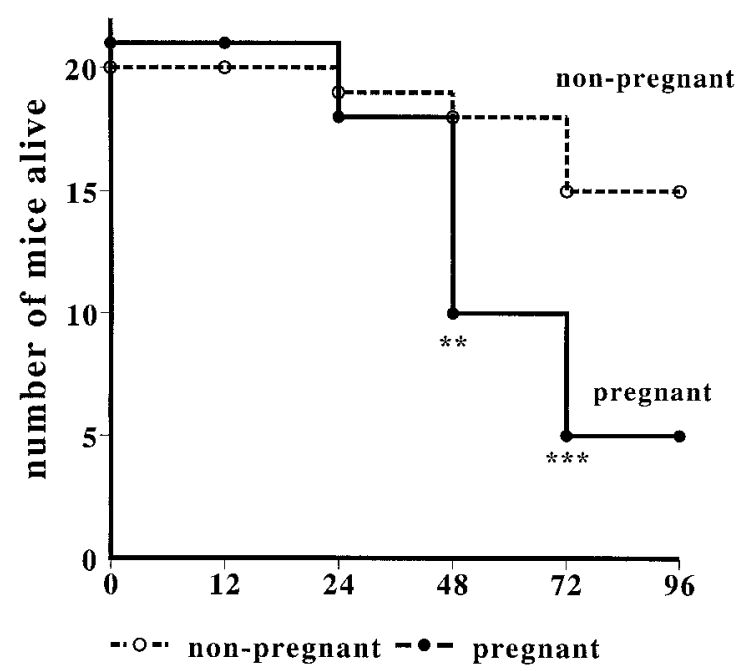

Figure 3 Pregnancy increases mortality in LPS-treated mice. Pregnant and non-pregnant mice were treated with $120 \mathrm{mg} / \mathrm{kg}$ LPS and observed for 2 weeks after LPS injection. There were no changes in lethality in either group after 96 h. $n=16$ per group. ${ }^{* *} P<0 \cdot 01,{ }^{* * *} P<0 \cdot 001$. shows that in agreement with this prediction, pregnancy enhanced the mortality rate in mice treated with $50 \mathrm{mg} / \mathrm{kg}$ LPS.

Effect of selective block of $\alpha_{2}$ and $\beta$-adrenoceptors and activation of $\beta$-adrenoceptors on LPS-induced cytokine production in non-pregnant and pregnant mice

Because in previous studies (Elenkov et al. 1995, 2000, Vizi et al. 1995, Haskó \& Szabó 1998, Szelényi et al. 2000) we showed that sympathetic outflow modulates LPSinduced cytokine production in non-pregnant mice via $\alpha_{2^{-}}$and $\beta$-adrenoceptor-mediated mechanisms, in the present study we tested whether such a modulation is operative in pregnant mice.

First, we used the selective $\alpha_{2}$-adrenoceptor antagonist CH-38083 (Vizi et al. 1986) to study the extent of immunomodulation by $\alpha_{2}$-adrenoceptors in non-pregnant and pregnant mice. CH-38083 (10 mg/kg, i.p.) injected $30 \mathrm{~min}$ before the LPS challenge $(10 \mathrm{mg} / \mathrm{kg})$ caused a significant suppression of TNF- $\alpha$ plasma level in both the non-pregnant and pregnant mice (Fig. 4). In addition, blockade of $\alpha_{2}$-adrenoceptors by $\mathrm{CH}-38083$ significantly enhanced the plasma level of IL-10 in non-pregnant but not in pregnant mice (Table 2). The $\beta$-adrenoceptor antagonist propranolol, administered at the dose of $10 \mathrm{mg} / \mathrm{kg} 30 \mathrm{~min}$ prior to the administration of LPS, completely antagonized the effect of LPS to increase the IL-10 level in the plasma (Table 2) in both non-pregnant and pregnant mice.

This was not the case when LPS was administered at a high dose mimicking severe toxemia (Table 2). The blockade of $\beta$-adrenoceptors by propranolol significantly increased the TNF- $\alpha$ level produced by LPS in the plasma from $4 \cdot 8 \pm 1 \cdot 1$ to $9 \cdot 9 \pm 1 \cdot 2 \mathrm{ng} / \mathrm{ml}(n=6, P<0 \cdot 05)$. This effect was also seen in pregnant mice (Fig. 4). In pregnant animals, when LPS was administered at a high dose $(50 \mathrm{mg} / \mathrm{kg})$, both propranolol and $\mathrm{CH}-38083$ failed to exert their effects: e.g. IL-10 plasma levels were not reduced or increased respectively (Table 2 ).

\section{Discussion}

In the early 1990s, it was proposed that the immune suppression observed in pregnancy does not affect all 


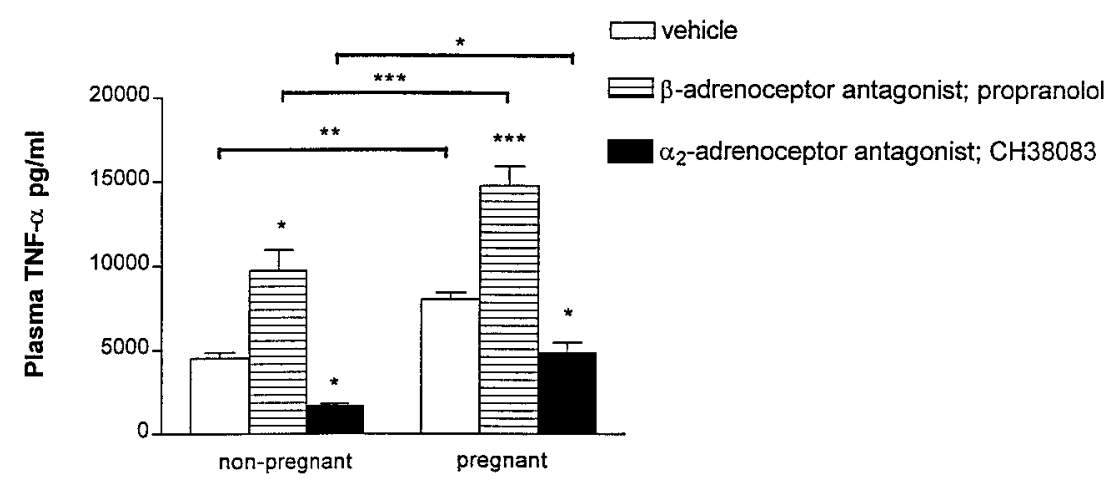

Figure 4 Boosting sympathetic outflow by blocking negative feedback modulation $(\mathrm{CH}-38083,10 \mathrm{mg} / \mathrm{kg})$ significantly reduces the TNF- $\alpha$ response to LPS $(10 \mathrm{mg} / \mathrm{kg}$, i.p.) in non-pregnant mice, but in the third trimester of pregnant mice it was significantly less effective. $\mathrm{CH}$-38083, a selective $\alpha_{2}$-adrenoceptor blocker, a drug able to block the negative feedback modulation of NE release from the sympathetic neurons, was injected i.p. $30 \mathrm{~min}$ prior to LPS administration. $n=6-10$ mice per group. Propranolol $(10 \mathrm{mg} / \mathrm{kg}$, i.p.), a $\beta$-adrenoceptor blocker administered 30 min earlier, significantly enhanced plasma TNF- $\alpha$ levels in response to LPS $(10 \mathrm{mg} / \mathrm{kg}$, i.p.) in both non-pregnant and pregnant animals. There is a significant difference between the two values. $n=6-10$ mice per group. ${ }^{*} P<0 \cdot 05$, ${ }^{* *} P<0 \cdot 01{ }^{* * *} P<0 \cdot 001$.

Table 2 Modulation of the LPS-evoked IL-10 levels in pregnancy (third trimester) by adrenergic drugs (10 mg/kg). Values are percent of controls \pm S.E.M. IL-10 levels were $4 \cdot 2 \pm 0 \cdot 2$ and $0 \cdot 6 \pm 0 \cdot 1 \mathrm{ng} / \mathrm{ml}$ in non-pregnant and pregnant mice $(P<0 \cdot 05)$. Number of mice in brackets

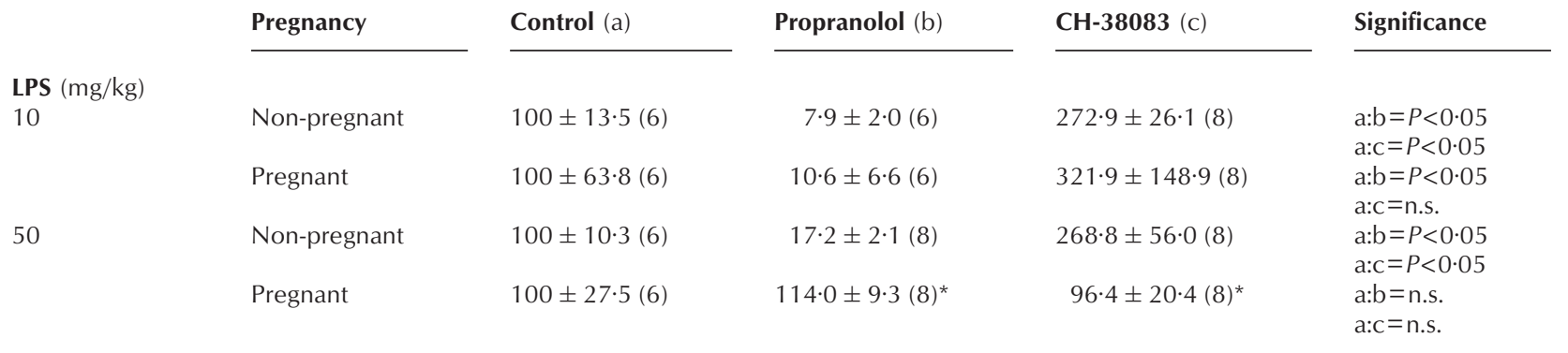

${ }^{*} P<0 \cdot 05$ between non-pregnant and pregnant animals.

lymphocyte functions (Wegmann et al. 1993). Rather, there seems to be a shift from a Th1-type cell-mediated immune response towards a Th2-type, antibody-mediated response. According to this hypothesis, the production of Th1-type cytokines (IFN- $\gamma$, IL-2 and TNF- $\alpha$ ) would be decreased, while the production of Th2 cytokines (IL-10, IL-4 and IL-5) would be increased in pregnant women. Our data obtained in this study demonstrate that systemic stimulation of the innate immune system with LPS results in an inverse cytokine profile, with increased TNF- $\alpha$ and IFN- $\gamma$, and decreased IL-10 level production. While our data seem to contradict the notion that pregnancy is characterized by enhanced IL-10 and decreased TNF- $\alpha$ and IFN- $\gamma$ production, this is not the case. That is because the concept of Th2 cytokine overproduction and deficient Th1-type cytokine production in pregnancy is mainly applicable to cells of the specific immune system (Sacks et al. 1999). Furthermore, such a shift towards the Th2 direction is most clearly manifest at the level of the maternal-fetal interface of normal pregnancy (Lin et al. 1993). However, in our model, we induced systemic production of cytokines by cells of the innate immune system, whereas in most earlier studies, the focus was on cytokines produced by $\mathrm{T}$ lymphocytes. Our results regarding the excessive production of proinflammatory cytokines are in good agreement with those that found that maternal innate (non-specific) immune responses are increased during pregnancy (Sacks et al. 1999, 2000). Furthermore, because we observed an overproduction of most proinflammatory cytokines, but a substantial decrease in IL-10 production, we propose that the concept of a general activation of the innate immune system needs to be further refined. That is, it appears that placental factors induce a change in the phenotype of the innate immune 
system from an anti-inflammatory to a proinflammatory one. Since IL-10 is one of the most important antiinflammatory factors that can downregulate most proinflammatory processes, it is plausible that the decrease of IL-10 production is central to the increased activity of innate immune system during pregnancy.

An important aspect of the excessive monocyte/ macrophage activation observed during pregnancy is the recently proposed notion that preeclampsia is a generalized intravascular, inflammatory response, resulting from the extreme activation of the non-specific immune system (Redman et al. 1999). This notion is supported by substantial evidence demonstrating that monocytes and granulocytes are activated during preeclampsia. For example, the increased expression of CD11b, CD14 and intracellular reactive oxygen species is even more pronounced in preeclampsia than in normal pregnancy (Redman et al. 1999). There is also increased release of TNF- $\alpha$ and IL-6 into the circulation (Vince et al. 1995). For these reasons, it was suggested that preexisting or concurrent infections could be an important precipitating factor in the induction of preeclampsia (Redman et al. 1999). This is consistent with an important rat model of preeclampsia, in which a single microdose of endotoxin triggers a preeclampsia-like state with hypertension and proteinuria that persists until the end of pregnancy (Faas et al. 1994). It is also noteworthy that the generalized Shwartzman reaction, which is induced by endotoxin, shares a number of pathophysiological phenomena with preeclampsia (McKay et al. 1953). These include disseminated intravascular coagulation and renal cortical necrosis (Beller \& Schoendorf 1972, Faas et al. 1994). The fact that similar to our observation in endotoxemia, there is a deficiency in IL-10 production and increase in TNF- $\alpha$ and IL-6 formation in preeclampsia (Hennessy et al. 1999) further substantiates the notion that preeclampsia arises when a universal maternal inflammatory response to pregnancy decompensates (Redman et al. 1999).

It is known that several factors can influence the development of inflammatory responses both in vitro and in vivo. Strong evidence is available that the effect of the central nervous system on immune responses is mediated by norepinephrine (NE) released from noradrenergic varicosities via activation of $\alpha_{2 \mathrm{~B}^{-}}$and $\beta_{2}$-adrenoceptors (Severn et al. 1992, Spengler et al. 1994, Elenkov et al. 1995, 1996, Vizi et al. 1995, Fessler et al. 1996, Straub et al. 1996, 2000, Suberville et al. 1996, van der Poll et al. 1996, Elenkov et al. 2000, Miller et al. 2000). Attention has been focused recently on $\alpha$ - and $\beta$-receptor-mediated modulation by endogenous NE of pro- and antiinflammatory cytokine production (Haskó et al. 1995, Fessler et al. 1996). For example, the $\beta$-adrenoceptor antagonist propranolol, removing the stimulatory effect of endogenously released NE on $\beta_{2}$-adrenoceptors expressed on cytokine-producing cells, increases the TNF- $\alpha$ (Elenkov et al. 1995) and inhibits the IL-10 production normally induced by LPS (Szelényi et al. 2000). On the other hand, when the sympathetic outflow, i.e. the release of endogenous NE, is increased by CH-38083, LPSinduced TNF- $\alpha$ levels are augmented and IL-10 levels are reduced (Szelényi et al. 2000). It was surprising to learn in this study that in pregnant animals, the modulation of both IL-10 and TNF- $\alpha$ production by endogenous NE via $\alpha_{2^{-}}$ or $\beta$-adrenoceptors does not operate. However, with the exception of $\alpha_{2}$-adrenoceptor-mediated modulation of IL-10 production, the effect of this pregnancy-induced unresponsiveness to endogenous NE was only apparent when a high dose of LPS was used. A possible explanation for this phenomenon is that the excessive release of endogenous NE caused by a high dose of LPS administration plus the effect of pregnancy result in a downregulation of both $\alpha_{2}$ and $\beta$-adrenoceptors that are the targets of the cytokine-modulatory effect of endogenous NE.

In conclusion, the present study was carried out to test whether pregnancy alters the production of cytokines to a systemic endotoxin challenge. The results of this study demonstrate that there is a substantial change in the cytokine profile in pregnant animals, which consists of an increase in proinflammatory cytokine production and decrease of the production of IL-10. Consistent with such a proinflammatory phenotype of cytokine production, pregnancy enhances LPS-induced mortality, which may have important implications for septic pregnant women. Further studies will be required to elucidate the causative factors and mechanisms responsible for the proinflammatory phenotype of the innate immune response in pregnancy.

\section{Acknowledgements}

The authors are indebted to Ms Julianna Benkõ and Ms Katalin Gazsi for their excellent technical help. This work was supported by grants from OTKA (Hungarian National Research Fund) and ETT (Medical Research Council) for E S V and OTKA No. T 29233 and ETT No. 034/99 for J S.

\section{References}

Beller FK \& Schoendorf T 1972 Augmentation of endotoxin-induced fibrin deposits by pregnancy and estrogen-pretreatment. Gynecologic Investigation 3 176-183.

Elenkov IJ, Haskó G, Kovacs KJ \& Vizi ES 1995 Modulation of lipopolysaccharide-induced tumor necrosis factor-alpha production by selective alpha- and beta-adrenergic drugs in mice. Journal of Neuroimmunology 61 123-131.

Elenkov IJ, Papanicolaou DA, Wilder RL \& Chrousos GP 1996 Modulatory effects of glucocorticoids and catecholamines on human interleukin-12 and interleukin-10 production: clinical implications. Proceedings of the Association of American Physicians 108 374-381.

Elenkov IJ, Hoffman J \& Wilder RL 1997 Does differential neuroendocrine control of cytokine production govern the expression of autoimmune diseases in pregnancy and the postpartum period? Molecular Medicine Today 3 379-383. 
Elenkov IJ, Wilder RL, Chrousos GP \& Vizi ES 2000 The sympathetic nerve - an integrative interface between two 'supersystems': the brain and the immune system. Pharmacological Reviews 52 595-638.

Faas MM, Schuiling GA, Baller JFW, Visscher CA \& Bakker WW 1994 A new animal model for human preeclampsia: ultra-low-dose endotoxin infusion in pregnant rats. American Journal of Obstetrics and Gynecology 171 158-164.

Faas MM, Schuiling GA, Linton EA, Sargent IL \& Redman CW 2000 Activation of peripheral leukocytes in rat pregnancy and experimental preeclampsia. American Journal of Obstetrics and Gynecology 182 351-357.

Fessler HE, Otterbein L, Chung HS \& Choi AM 1996 Alpha-2 adrenoceptor blockade protects rats against lipopolysaccharide. American Journal of Respiratory and Critical Care Medicine 154 $1689-1693$

Haskó G \& Szabó C 1998 Regulation of cytokine and chemokine production by transmitters and co-transmitters of the autonomic nervous system. Biochemical Pharmacology 56 1079-1087.

Haskó G, Elenkov IJ, Kvetan V \& Vizi ES 1995 Differential effect of selective block of alpha 2-adrenoreceptors on plasma levels of tumour necrosis factor-alpha, interleukin-6 and corticosterone induced by bacterial lipopolysaccharide in mice. Journal of Endocrinology 144 457-462.

Haskó G, Szabó C, Németh ZH, Kvetan V, Pastores SM \& Vizi ES 1996 Adenosine receptor agonists differentially regulate IL-10, TNF- $\alpha$, and nitric oxide production in RAW $264 \cdot 7$ macrophages and in endotoxemic mice. Journal of Immunology 157 4634-4640.

Haskó G, Szabó C, Nemeth ZH, Salzman AL \& Vizi ES 1998 Stimulation of $\beta$-adrenoceptors inhibits endotoxin-induced IL-12 production in normal and IL-10 deficient mice. Journal of Neuroimmunology 88 57-61.

Haskó G, Kuhel DG, Chen JF, Schwarzschild MA, Deitch EA, Mabley JG, Marton A \& Szabó C 2000 Adenosine inhibits IL-12 and TNF- $\alpha$ production via adenosine $\mathrm{A}_{2 \mathrm{a}}$ receptor-dependent and independent mechanisms. FASEB Journal 14 2065-2074.

Hennessy A, Pilmore HL, Simmons LA \& Painter DM 1999 A deficiency of placental IL-10 in preeclampsia. Journal of Immunology 163 3491-3495.

Koumandakis E, Koumandaki I, Kaklamani E, Sparos L, Aravantinos D \& Trichopoulos D 1986 Enhanced phagocytosis of mononuclear phagocytes in pregnancy. British Journal of Obstetrics and Gynaecology 93 1150-1154.

Lin H, Mosmann TR, Guilbert L, Tuntipopipat S \& Wegmann TG 1993 Synthesis of T helper 2-type cytokines at the maternal-fetal interface. Journal of Immunology 151 4562-4573.

McKay DG, Merril SJ, Weiner AE, Hertig AT \& Reid DE 1953 The pathologic anatomy of eclampsia, bilateral renal cortical necrosis, pituitary necrosis, and other acute fatal complications of pregnancy, and its possible relationship to the generalized Shwartzman phenomenon. American Journal of Obstetrics and Gynecology 66 $507-539$.

Medawar PB 1953 Some immunological and endocrinological problems raised by the evolution of viviparity in vertebrates. Symposia of the Society for Experimental Biology 7 320-328.

Miller LE, Justen HP, Scholmerich J \& Straub RH 2000 The loss of sympathetic nerve fibers in the synovial tissue of patients with rheumatoid arthritis is accompanied by increased norepinephrine release from synovial macrophages. FASEB Journal 14 2097-2107.

Mori W 1981 The Shwartzman reaction: a review including clinical manifestations and a proposal for a univisceral or single organ third type. Histopathology $\mathbf{5}$ 113-126.
Ostensen M 1999 Sex hormones and pregnancy in rheumatoid arthritis and systemic lupus erythematosus. Annals of the New York Academy of Sciences 876 131-143.

Redman CWG, Sacks GP \& Sargent IL 1999 Preeclampsia: an excessive maternal inflammatory response to pregnancy. American Journal of Obstetrics and Gynecology 180 499-506.

Sacks GP, Studena K, Sargent K \& Redman CW 1998 Normal pregnancy and preeclampsia both produce inflammatory changes in peripheral blood leukocytes akin to those of sepsis [see comments]. American Journal of Obstetrics and Gynecology 179 80-86.

Sacks GP, Sargent I \& Redman C 1999 An innate view of human pregnancy. Immunology Today 20 114-118.

Sacks GP, Sargent I \& Redman C 2000 Innate immunity in pregnancy. Immunology Today 21 200-201.

Severn A, Rapson NT, Hunter CA \& Liew FY 1992 Regulation of tumor necrosis factor production by adrenaline and beta-adrenergic agonists. Journal of Immunology 148 3441-3445.

Spengler RN, Chensue SW, Giacherio DA, Blenk N \& Kunkel SL 1994 Endogenous norepinephrine regulates tumor necrosis factoralpha production from macrophages in vitro. Journal of Immunology 152 3024-3031.

Straub RH, Herrmann M, Frauenholz T, Berkmiller G, Lang B, Scholmerich J \& Falk W 1996 Neuroimmune control of interleukin6 secretion in the murine spleen. Differential beta-adrenergic effects of electrically released endogenous norepinephrine under various endotoxin conditions. Journal of Neuroimmunology 71 37-43.

Straub RH, Linde HJ, Mannel DN, Scholmerich J \& Falk W 2000 A bacteria-induced switch of sympathetic effector mechanisms augments local inhibition of TNF-alpha and IL-6 secretion in the spleen. FASEB Journal 14 1380-1388.

Suberville S, Bellocq A, Fouqueray B, Philippe C, Lantz O, Perez J \& Baud L 1996 Regulation of interleukin-10 production by beta-adrenergic agonists. European Journal of Immunology 26 2601-2605.

Szelényi J, Kiss JP \& Vizi ES 2000 Differential involvement of sympathetic nervous system and immune system in the modulation of TNF-alpha production by alpha2- and beta-adrenoceptors in mice. Journal of Neuroimmunology 103 34-40.

van der Poll T, Coyle SM, Barbosa K, Braxton CC \& Lowry SF 1996 Epinephrine inhibits tumor necrosis factor-alpha and potentiates interleukin-10 production during human endotoxemia. Journal of Clinical Investigation 97 713-719.

Vince GS, Starkey PM, Austgulen R, Kwiatkowski D \& Redman CW 1995 Interleukin-6, tumour necrosis factor and soluble tumor necrosis factor receptors in women with preeclampsia. British Journal of Obstetrics and Gynaecology 102 20-25.

Vizi ES, Harsing LG Jr, Gaal J, Kapocsi J, Bernath S \& Somogyi GT 1986 CH-38083, a selective, potent antagonist of alpha-2 adrenoceptors. Journal of Pharmacology and Experimental Therapeutics 238 701-706.

Vizi ES, Orso E, Osipenko ON, Hasko G \& Elenkov IJ 1995 Neurochemical, electrophysiological and immunocytochemical evidence for a noradrenergic link between the sympathetic nervous system and thymocytes. Neuroscience 68 1263-1276.

Wegmann TG, Lin H, Guilbert L \& Mosmann TR 1993 Bidirectional cytokine interactions in the maternal-fetal relationship: is successful pregnancy a Th2 phenomenon? Immunology Today $\mathbf{1 4}$ 353-356.

Received 13 June 2001

Accepted 20 July 2001 